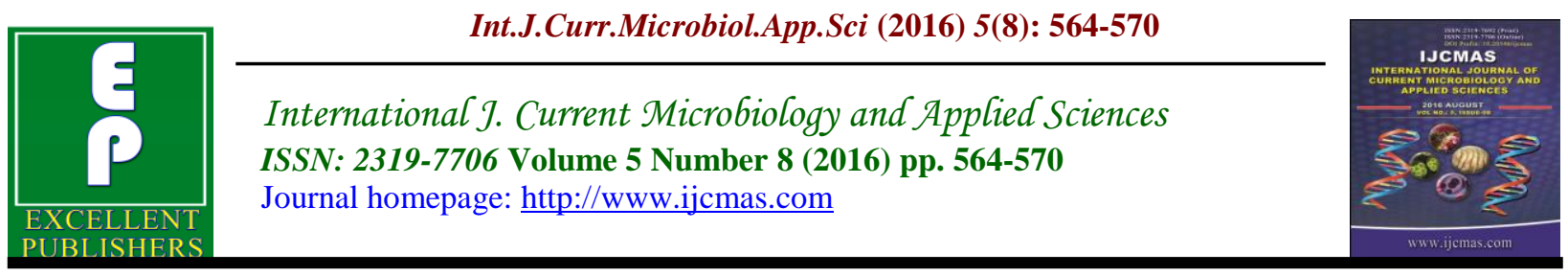

Original Research Article

http://dx.doi.org/10.20546/ijcmas.2016.508.062

\title{
GeneXpert MTB/RIF Sputum MTB Detection and Human Immunodeficiency Virus Seroprevalence among Patients with Presumptive Pulmonary Tuberculosis at a New Teaching Hospital in North-Central Nigeria
}

\author{
T.P. Mbaave ${ }^{1 *}$, T.J. Igbudu ${ }^{2}$, L. Egwuda ${ }^{2}$, O. Audu ${ }^{3}$ and G.T. Jombo ${ }^{4}$ \\ ${ }^{1}$ Department of Medicine, Benue State University Teaching Hospital Makurdi, \\ Benue State Nigeria \\ ${ }^{2}$ Department of Family Medicine, Benue State University Teaching Hospital Makurdi, \\ Benue State Nigeria \\ ${ }^{3}$ Department of Epidemiology and Community Medicine, Benue State University Teaching \\ Hospital Makurdi, Benue State Nigeria \\ ${ }^{4}$ Department of Medical Microbiology, Benue State University Teaching Hospital \\ Makurdi, Benue State Nigeria \\ *Corresponding author
}

Keywords

Sputum MTB

Detection,

Human

Immunodeficiency

Virus,

Article Info

Accepted:

23 July 2016

Available Online:

10 August 2016
A B S T R A C T

The GeneXpert MTB/RIF (GeneXpert) test, a nucleic acid amplification test for the diagnosis of pulmonary tuberculosis in both HIV seronegative and serpositive patients is gradually replacing sputum smear microscopy even in resourceconstrained developing nations. To assess the prevalence of GeneXpert sputum positive TB and sero-prevalence of human immunodeficiency virus (HIV) among patients with presumptive pulmonary tuberculosis (PTB) in a teaching hospital in North central Nigeria. This was an operational based prospective laboratory study carried out from Febraury, 2014 to May, 2015 at the Benue State University Teaching Hospital, Makurdi, North-central Nigeria. The GeneXpert technology and Determine/Stat pak were used for the diagnosis of PTB and HIV respectively. Three hundred (300) presumptive PTB cases were recruited, $160(53.3 \%)$ were males and 140 (46.7\%) were females. Mean age of 39.81 years. Seventy (23.3\%) tested positive for PTB. More than half $(56.3 \%)$ were positive for HIV with females most vulnerable. PTB/HIV co-infection was found in 34/300 (11.33\%) of the patients. The positivity for PTB, HIV and co-infection were all skewed to age group of 31-40 years. The study revealed a high prevalence of GeneXpert sputum positive PTB, HIV and co-infection among presumptive PTB cases in Makurdi.

\section{Introduction}

Pulmonary tuberculosis (PTB) is a chronic communicable disease. The infection (latent tuberculosis) affects approximately onethird of the world's population with a current estimate of 9.6 million cases of active disease and 1.5 million in the year 2014 posing a major public health challenge in the resource-constrained developing 
nations (WHO, 2015; Mesfin et al., 2015; Muvunyi et al., 2010; Nwadike et al., 2013; Sia et al., 2011). Historically, the scourge of PTB declined in the late 70s especially in developed countries until the advent of HIV which significantly increased its global incidence and altered its presentation consequently posing major clinical and laboratory diagnostic challenges especially in the resource-constrained nations. The problem is compounded by emergence of multidrug resistant tuberculosis (MDRTB) and extensively drug resistant tuberculosis (XDRTB). The clinical criteria for presumptive PTB suspect in adults includes chronic cough (usually more than two weeks duration) with or without production of sputum, haemoptysis, weight loss, low grade evening pyrexia, drenching night sweats and anorexia. In the paediatric population, the tuberculosis score chart is used which is essentially a modification of the symptoms observed in adults. The WHO recommended diagnosis of PTB until recently was based on these clinical presentations and sputum smear microscopy with its attendant shortcoming of low sensitivity which made the disease under reported and under diagnosed (Piatek et al., 2013; WHO, 2015).

Since the discovery of the causative bacilli by Robert Koch in 1882, the definitive diagnosis of PTB has evolved and now revolves round detection of Acid Fast Bacilli (AFB) in the sputum of suspected patients with clinical symptoms suggestive of the disease. In attempt to identify the bacilli, several sputum smear staining techniques have been implored which include: Carbolfuchin methods (e.g. Ziehl-Neelsen and Kinyoun methods) and the use of fluorochrome methods with fluorescence microscopy which is preferred to the Carbolfuchin methods because of its higher sensitivity Amongst the procedures available, smear microscopy has been the main diagnostic tool in most resourceconstrained developing nations over the years until recently when newer diagnostic modalities including the molecular techniques like the GeneXpert MTB/RIF were introduced (Piatek et al., 2013; Chinnakali et al., 2014). This recently introduced GeneXpert technology is used in the diagnosis of pulmonary tuberculosis from sputum and for detection of Rifampicin resistance as a surrogate for MDRTB (Multi-Drug Resistant Tuberculosis). It has higher sensitivity especially in HIV patients and shorter time to result compared to ZiehlNelson stain in addition to the advantage of detecting Rifampicin resistance (Mustapha Gidado et al., 2014; Neeraj Raizada et al., 2015). Another advantage is that it requires lesser number of bacilli for detection. While smear microscopy requires 10,000 TB bacilli per $\mathrm{ml}$ of sputum to be detected/positive, GeneXpert MTB/RIF requires $130 \mathrm{~TB}$ bacilli per $\mathrm{ml}$ of sputum for a positive result. Studies have shown that samples for the GeneXpert method could also come from urine, stool, blood and other body fluids apart from sputum thereby improving the diagnosis of both pulmonary, extra pulmonary tuberculosis and detection of drug resistance. This technique involves the use of cartridge based nucleic acid amplification with basic principle of Polymerase Chain Reaction (PCR). This innovative technology is also new to many developing nations including Nigeria and by extension to North-Central Nigeria where this study was carried out. As a result, there is paucity of local literature (any facts backing this). Exploring the use of this technology will improve diagnosis, help in reducing patients waiting time, thus shortening the time from diagnosis to treatment and ultimately reducing total cost of management of the patients.

This pioneer study in this centre will determine prevalence of PTB using 
GeneXpert/RIF technology and the seroprevalence of HIV among the presumptive and confirmed PTB patients attending the Benue State University Teaching Hospital, North central Nigeria.

\section{Materials and Methods}

\section{Study area}

The study was carried out at Benue State University Teaching Hospital (BSUTH) a newly established tertiary health institution in Makurdi, Benue state; North-Central Nigeria, located along a major road linking the northern to the southern part of the country. The state has an estimated population of 4.25 million (2006 National Population Census) (Egwuda et al., 2015). The hospital serves Benue and the neighbouring states of Taraba, Nassarawa, and Cross River.

\section{Study design and population}

This was operational prospective laboratory based study. The study population were patients who presented to the BSUTH with cough of 2 or more weeks duration irrespective of other complaints. They were recruited from general out patients unit of Family Medicine Department, HIV and TB clinics, the hospital wards and referrals from private and public hospitals.

\section{Inclusion criteria}

Cough of 2 weeks duration or more, and consent for participation.

\section{Exclusion criteria}

Patients with cough of known aetiology, inability to produce sputum and refusal of consent.
Ethical considerations: Ethical approval for the study was obtained from the Ethical committee of the Benue State University Teaching Hospital, Makurdi.

Study protocol: The study was conducted at the Chest unit of the hospital between February, 2014 and May, 2015. Consecutive eligible respondents seen over the study period were enrolled after they were counselled and their informed consent dully obtained. Each patient was registered and given a presumptive TB case clinic number. Their socio-demographic characteristics and clinical history were obtained and sputum samples were collected in line with the National Tuberculosis and Leprosy Programme guidelines (standard operative procedures). Three-five (3-5) $\mathrm{mls}$ of deep sputum specimens were collected from the patients in clean, dry, wide necked and leakproof containers and submitted to the laboratory immediately. A finger prick was performed to get blood for HIV screening after counselling.

Laboratory analysis: The sputum specimens for $\mathrm{TB}$ were processed and subsequently analysed using the polymerase chain reaction cartridge-based GeneXpert machine according to its standard operating procedures. Determine and Stat Pakwere used for HIV screening using standard protocol.

Patients who tested positive for TB were commenced on anti-TB medications based on the national protocol and those positive for HIV were referred to anti-retroviral (ART) clinic of BSUTH for appropriate treatment.

Statistical analysis: Data was summarized in a spreadsheet, collated and analysed using statistical Package for Social Sciences (SPSS) version 20.0.A descriptive analysis 
was performed on each variable and Chi square $\left(\mathrm{X}^{2}\right)$ was used to compare relationships between categorical variables. Associations and differences were considered statistically significant if $p$-value is less than 0.05 .

\section{Results and Discussion}

Of the 300 patients recruited for the study, $160(53.3 \%)$ were males and $140(46.7 \%)$ females giving a ratio of 1.1:1. The age range of patients seen was from 6-106 years of age with mean age of 39.81 years $(\mathrm{SD}=$ 15.82 years). Table1The paediatric age group (0-15years) accounted for $15(5 \%)$ while the adult population accounted for 285 (95\%). Table 2

Seventy patients tested sputum positive using GeneXpert methodology for PTB giving a prevalence rate at $23.3 \%$. Among these patients, there were more males (47) than their female (23) counterparts with a ratio of $2: 1$. More than half $(169 / 300)$ of the PTB suspects comprising of 73 males and 140 females were positive for HIV giving a prevalence of $56.3 \%$. The male to female ratio was 1:9. The prevalence of co-infection with PTB and HIV among the PTB suspects was $34 / 300$ (11.3\%), made up of 20 males and 14 females with a ratio of 1.4: 1 . Prevalence of HIV in the sputum positive (PTB) patients was $48.0 \%$ (34/70). Table1

The study revealed the age group of $31-40$ years as the most affected $(27.3 \%)$. This age group also had most of the patients that were GeneXpert sputum positive PTB 25/70 $(35.7 \%, \mathrm{p}=0.05)$, and 57/169(33.7\%, $\mathrm{p}=0.05)$ that were HIV positive, with PTB/HIV co-infection rate of 16/34 (47.1\%, $\mathrm{P}=0.06$.) (Table1\&2).

In our study, the prevalence of positive PTB by GeneXpert was $23.3 \%$. An earlier study by Nwadioha et al., 2014 in two different hospitals in Makurdi in 2012 found the prevalence rate of GeneXpert/RIF positive pulmonary tuberculosis of $21.5 \%$ which is similar indicating reliability of the machine (Nwadioha et al., 2014). The current national prevalence of tuberculosis for Nigeria is 332/100,000. The high prevalence in this study can be explained by the fact that these are a specific group of subjects who were already sick and attending hospital. The prevalence of PTB $(23.3 \%)$ is found more than-the prevalence of $16.5 \%$ in Yirgalem, $17.3 \%$ in Rwanda, $9.2 \%$ in Ethiopia and $13 \%$ in Ghana (Zeynudin et al., 2012; Acquah et al., 2012). This difference may be due to the fact that these studies/centres used sputum AFB microscopy for detecting the tuberculin bacilli which is less sensitive to the GeneXpert technology used in this study. Another reason for the higher prevalence could be the high HIV burden in the population in which this study was carried out compared to the others. This is buttressed by the finding in this study that $48 \%$ of PTB patients were HIV infected showing that tuberculosis in this population is HIV driven.

Though this study did not do any comparism, Gidado et al., 2014 in Abuja reported a $17 \%$ diagnostic yield over sputum AFB test, while another large scale study in India demonstrated superiority of GeneXpert over sputum smear microcopy in detecting MTB among co infected patients apart from the rapid turn out time and RIF resistance detection.

In other parts of the country (Nigeria), Wasa et al., 2013 in Gombe reported a higher PTB prevalence of $32.2 \%$ and also observed that females were more vulnerable than males contrally to findings in this study, where the prevalence was lower with males preponderance (Wasa et al., 2013). In 
Nnewi South East Nigeria, Okonkwo et al., 2013 reported a PTB prevalence of $15.4 \%$ with more males than female (.Wasa et al., 2013). This was observed to be less than the prevalence in this study. The use of a less sensitive method of detection of tuberculin bacilli (sputum smear microscopy) in Nnewi and the lower prevalence of HIV in the area could explain the relatively low prevalence reported. Despite the difference in the methods in both studies, it was observed that more males were also affected than their female counterparts. Another similar study in Gboko (a neighbouring town to Makurdi) by Aernan et al., 2010 with similar demographic characteristics of subjects with similar findings reported much higher prevalence of PTB as $56.3 \%$ with the age group of 31- 40 years being most vulnerable (Aernan et al., 2010).

Table.1 Sex distribution and laboratory results of patients $(n=300)$

\begin{tabular}{|l|l|l|l|l|l|l|}
\hline & GeneXpert Results *** & \multicolumn{2}{l|}{ HIV Status ** } & \multicolumn{2}{l|}{ PTB/HIV co-infection status $*$} \\
\hline Sex & Negative & Positive & Negative & Positive & $\begin{array}{l}\text { No } \\
\text { infection }\end{array}$ & $\begin{array}{l}\text { Presence of co- } \\
\text { infection }\end{array}$ \\
\hline Male & 113 & 47 & 87 & 73 & 140 & 20 \\
\hline Female & 117 & 23 & 44 & 96 & 126 & 14 \\
\hline Total & $\mathbf{2 3 0}$ & $\mathbf{7 0}$ & $\mathbf{1 3 1}$ & $\mathbf{1 6 9}$ & $\mathbf{2 6 6}$ & $\mathbf{3 4}$ \\
\hline
\end{tabular}

***PTB: $\mathrm{X}^{2}=6.996, \mathrm{df}=1, \mathrm{P}=0.008$, Fisher's exact test $=0.006$ (Significant Association)

**HIV: $\mathrm{X}^{2}=15.982, \mathrm{df}=1, \mathrm{P}=0.000$, Fisher's exact test $=0.000$ (Significant Association)

*PTB/HIV co-infection: $\mathrm{X}^{2}=0.464, \mathrm{df}=1, \mathrm{P}=0.496$, Fisher's exact test $=0.310$ (No Significant Association)

Table.2 Age distribution and laboratory results outcome of patients $(n=300)$

\begin{tabular}{|l|l|l|l|l|l|l|}
\hline & \multicolumn{2}{|l|}{ GeneXpert Result IIIII } & \multicolumn{2}{l|}{ HIV Status IIII/HIV co-infection status II } \\
\hline Age (years) & Negative & Positive & Negative & Positive & $\begin{array}{l}\text { No } \\
\text { infection }\end{array}$ & $\begin{array}{l}\text { Presence of co- } \\
\text { infection }\end{array}$ \\
\hline $0-10$ & 9 & 0 & 3 & 6 & 9 & 0 \\
\hline $11-20$ & 14 & 1 & 5 & 10 & 14 & 1 \\
\hline $21-30$ & 41 & 25 & 30 & 36 & 55 & 11 \\
\hline $31-40$ & 57 & 25 & 25 & 57 & 66 & 16 \\
\hline $41-50$ & 51 & 9 & 25 & 35 & 56 & 4 \\
\hline $51-60$ & 36 & 6 & 25 & 17 & 41 & 1 \\
\hline $61-70$ & 13 & 4 & 11 & 6 & 16 & 1 \\
\hline $71-80$ & 6 & 0 & 4 & 2 & 6 & 0 \\
\hline$\geq 81$ & 3 & 0 & 3 & 0 & 3 & 0 \\
\hline Total & $\mathbf{2 3 0}$ & $\mathbf{7 0}$ & $\mathbf{1 3 1}$ & $\mathbf{1 6 9}$ & $\mathbf{2 6 6}$ & $\mathbf{3 4}$ \\
\hline
\end{tabular}

IIITI PTB: $\mathrm{X}^{2}=22.211, \mathrm{df}=8, \mathrm{P}=0.005$ (Significant Association)

III HIV: $\mathrm{X}^{2}=19.528, \mathrm{df}=8, \mathrm{P}=0.012$ (Significant Association)

II PTB/HIV co-infection: $\mathrm{X}^{2}=15.105, \mathrm{df}=8, \mathrm{P}=0.057$ (Not Significant Association)

In this study the prevalence of HIV among PTB suspects was $56.33 \%$. This was observed to be much higher than from the work done in Nnewi (11.9\%) (Okonkwo et al., 2013). Again, the relatively higher prevalence of HIV in Benue State may have been responsible for this difference. The two studies and others also found higher prevalence in females. This can be explained partly by the lower socio-economic status of the women in this region compared to men and a larger exposed surface area of the 
vagina to infected semen during sexual intercourse apart from the fact that women have better health seeking behaviour than males and hence are likely to have been captured in the statistics. The lower literacy level in this study population means the women are unable to negotiate safer sex practises like the use of condoms.

The study also reported PTB/HIV coinfection rate of $11.3 \%$ in ptb suspects with more males than females affected. This rate was observed to be more than the reported rates in Nnewi (1.4\%) which also had more males than females. The geographically strategic location of the study area may also explain this high rates of co-infection reported as it has high influx of human traffic especially long distance truck drivers who are involved in the distribution of diverse farm produce and other products to different parts of the country.

The age group 31-40 years had more patients who were positive for HIV, PTB and also had PTB/HIV co-infection. The age group is the most sexually active and therefore more at risk of HIV infection. This group is also the reproductive age group. This calls for urgent measures like public education, prompt detection and treatment of both diseases to prevent escalation of poverty due to an unhealthy and unproductive work force. Both conditions are also associated with sub-fertility. This study proves that the GeneXpert method is a major technological advancement for TB diagnostics especially that the method is not only more sensitive and specific (comparable with sputum culture sensitivity) but also reduces the time it takes arriving at the diagnosis to about two hours making the whole process more cost effective.

In conclusion, the present study revealed a high prevalence of sputum positive PTB among presumptive PTB cases in Benue state using the GeneXpert/RIF test method and high prevalence of HIV among presumptive PTB cases and a high rate of $\mathrm{PTB} / \mathrm{HIV}$ co-infection. The reproductive age group of 31-40 years was the most affected. It is recommended that the use of GeneXpertMTB/RIF technology should be expanded to cover the state to improve case detection and treatment of TB and MDR TB. HIV preventive and treatment services should be scared up and intergrated with TB services to reduce the burden of tuberculosis.

\section{References}

Acquah, S.E.K., Quaye, L., Ziem, J.B., Kuugbee, E.D., Iddrisu, A.Y., Sagoe, K. 2012. Prevalence of smear positive tuberculosis among outpatient attendees, the case of Tamale Teaching Hospital. J. Med. Biomed. Sci., 1(4): 34-41.

Aernan, P.T., Akande, T., Yange, T.S. 2010. TB/HIV co-infection rates among patients attending secondary health centres in Gboko metropolis of Benue State, Nigeria. J. Med. Appl. Biosci., 2: 67-71.

Ali, H., Zeynudin, A., Mekonnen, A., Abera, S., Ali, S. 2012. Smear positive pulmonary tuberculosis (PTB) prevalence amongst patients at Agaro Teaching Health Centre, South West Ethiopia. Ethiop. J. Health Sci., 22(1): 71-76.

Chinnakali, P., Selvaraj, K., Thekkur, P., Ramasamy, G., Thulasingam, M., Vasudevan, K. 2014. Age and sex differences in sputum smear microscopy results for acid fast bacilli in a tertiary care centre, South India. $J$. Respiratory Med., Accessed at http://dx.doi.org/10.1155/2014/674942 on 22nd June, 2015, Clin. Proc., 86(4): 348-361.

Egwuda, L., Igbudu, T.J., Omokhua, O.E., 
Izeji, R. 2015. Primary care patients' internet use in a part of middle-belt region of Nigeria. Asian Pac. J. Health Sci., 2(4S): 1926.

Mayo Uzoewulu, N.G., Ibeh, I.N., Lawson, L., Goyel, M., Umenyonu, N., Ofiaeli, R.O. 2014. Drug resistant mycobacterium tuberculosis in tertiary hospital South East, Nigeria. J. Med. Microb. Diagn., 3: 2.

Mesfin, W.H., Teshome, B.A. 2015. Prevalence of rifampicin mono resistant mycobacterium tuberculosis among suspected cases attending at Yirgalem Hospital. Clin. Med. Res., 4(3): 75-78.

Mustapha Gidado, Olajumoke Onazi, Olusegun Obasanya. et al. 2014. Assessing the Effectiveness of Xpert MTB/RIF in the Diagnosis of TB Among HIV Smear Negative TB Patients in Nigeria. J. Health Sci., 2: 145-151.

Muvunyi, C.M., Masaisa, F., Bayingana, C., Musemakweri, A., Mutesa, L., Hernandez, T.C. 2010. Prevalence and diagnostic aspects of sputum smear positive tuberculosis cases at a tertiary care institution in Rwanda. African $J$. Microbiol. Res., 4(2): 088-091.

Neeraj Raizada, Kuldeep Singh Sachdeva, Achuthan Sreenivas, et al. 2015. Catching the Missing Million: Experiences in Enhancing TB \& DRTB Detection by Providing Upfront Xpert MTB/RIF Testing for People Living with HIV in India. PLoS One, 10(2): e0116721. Published online
2015 Feb 6. doi: 10.1371/journal.pone.0116721

Nwadike, V.U., Mbata, G.C., Kalu, I.E., Ojide, K.C., Nweke, I.G., Nwokeji, C.M. 2013. Sputum smear positive tuberculosis among tuberculosis patients in a tertiary hospital in South Eastern Nigeria. Sky J. Med. Med. Sci., 1(5): 20-24.

Nwadioha, S.I., E.O.P. Nwokedi, G.C. Ezema. et al. 2014. Drug Resistant Mycobacterium tuberculosis in Benue, Nigeria British Microbiol. Res. J., 4(9): 988-995, .

Okonkwo, R.C., Anyabolu, A.E., Ifeanyichukwu, M., Kalu, S.O., Onwunzo, M.C., Chukwuka, C. 2013. Prevalence of HIV infection in pulmonary tuberculosis suspects; assessing the Nnamdi Azikiwe University Teaching Hospital, Nnewi, Nigeria, 14: 87-90.

Piatek, A.S., van Cleeff, M., Alexander, H., Coggin, W.L., Rehr, M., van Kampen, S. et al. 2013. GeneXpert for diagnosis: planned and purposeful implementation. Glob. Health Sci. Pract., 1(1): 18-23.

Sia, I.G., Wieland, M.L. 2011. Current concepts in the management of tuberculosis.

Wasa, A.A., Raj, K.P., Bello, Y.B. 2013. Incidence of tuberculosis among HIV patients attending general hospital Bajoga. IOSR J. Pharmacy and Biol. Sci., 7(5): 69-72.

WHO. WHO Global Tuberculosis Report 2015.

\section{How to cite this article:}

Mbaave, T.P., T.J. Igbudu, L. Egwuda, O. Audu and Jombo, G.T. 2016. GeneXpert MTB/RIF Sputum MTB Detection and Human Immunodeficiency Virus Seroprevalence among Patients with Presumptive Pulmonary Tuberculosis at a New Teaching Hospital in North-Central Nigeria. Int.J.Curr.Microbiol.App.Sci. 5(8): 564-570.

doi: http://dx.doi.org/10.20546/ijcmas.2016.508.062 